\title{
Influences of microalgae biomass on the thermal behaviour of waste coal fines
}

\section{Hope Baloyi*, Gary Dugmore}

InnoVenton and the Downstream Chemicals Technology Station, Department of Chemistry, Faculty of Science, Nelson Mandela University, PO Box 77000, Port Elizabeth 6031, South Africa

\begin{abstract}
For this study, waste coal fines were treated with live microalgae slurry at varying biomass ratios to form coal-microalgae blends. The parent samples and the coal-microalgae blends were analysed for their proximate, ultimate and calorific values. Thermogravimetric experiments were performed on the parent samples and coal-microalgae blends under inert conditions. The aim was to investigate the effects of loading live microalgae slurry onto the waste coals with respect to the overall chemical and thermal characteristics of the coal. Based on the analysed results, the blending of microalgae slurry with coal has been shown to enhance thermal decomposition of coal. Coal-microalgae blends have a higher hydrogen content and volatile matter content than coal. Moreover, the presence of microalgae results in faster rates of decomposition at lower temperatures $\left(200-400{ }^{\circ} \mathrm{C}\right)$, and lower residual mass fraction. The blending of microalgae slurries with waste coal appears to be suitable for enhancing the thermal reactivity of waste coal as well as improving the thermal conversion of waste coal.
\end{abstract}

Keywords: coal-microalgae blends, microalgae biomass, waste coal, thermal

\section{Highlights}

- Enhance the ignitability and thermal conversion of the waste coal

- Systematic increase in the hydrogen content

- $10 \%$ loadings improve the thermal degradation of coal.

- Microalgae facilitates the conversion of coal fines

- Volatiles driven-off from microalgae biomass

Journal of Energy in Southern Africa 30(1): 1-7

DOI: http://dx.doi.org/10.17159/2413-3051/2019/v30i1a5452

Published by the Energy Research Centre, University of Cape Town ISSN: 2413-3051 http://journals.assaf.org.za/jesa

Sponsored by the Department of Science and Technology

\footnotetext{
* Corresponding author: Tel.:+27 (0)41 504 2380;

email: baloyih82@gmail.com
} 


\section{Introduction}

In South Africa, coal is the most accessible and consumed primary fuel resource, accounting for more than $70 \%$ of the country's total primary energy needs (BP, 2015; WCI, 2012). Despite the high dependence on coal, its utilisation and processing poses serious risks, such as the release of pollutant gases (methane and oxides of sulphur and nitrogen), and disposal of particulate matter in the environment (WCI, 2007). Moreover, coal mining and beneficiation have resulted in the accumulation of waste coal generated as by-products, estimated to be approximately 60 million tons generated per year, adding to the waste coal stockpile (Gaqa and Watts, 2018). Waste coals are generally of low quality and are unusable due to their poor thermal performance and undesirable chemical properties (i.e. high sulphur content and high ash yields), and thus are uneconomical (Gaqa and Watts, 2018). As part of the efforts to promote the utilisation of cleaner and sustainable coal technologies, the South African Department of Energy, through its 1998 White Paper on Energy Policy (DME, 1998), recognised waste coals as future reserves of low-grade coals, and has encouraged the utilisation of waste coal streams.

Waste coal fines contain exploitable carbon, and therefore their effective recovery and upgrading can potentially reduce the environmental burden associated with their disposal and generation of revenue from the utilisation of the waste coal to yield typical coal products. One of the ways of utilising these coals would be through co-processing with a biomass feedstock. Biomass is deemed carbon neutral, and can potentially reduce the release of unwanted gas pollutants when co-fired with coal (Chao et al., 2008). The added advantage of biomass is the fact that it is thermally reactive (Kirtania et al., 2013; Chen et al., 2012), and contains relatively low amounts of sulphur, high amounts of hydrogen and has a high hydrogen-tocarbon (H/C) ratio (Debiagi et al., 2007). Furthermore, the thermal reactivity of biomass would allow the substantial release of volatile components in the coal during co-processing, which in turn could assist in the conversion of coal (Blesa et al., 2003; Fermoso et al., 2010). Also, the presence of hydrogen-rich light molecules released from biomass may influence the thermal processing of coal (Zhang et al., 2007).

Biomass is known to possess different chemical properties to coal, and undergoes independent thermal degradation during co-processing with coal, and as a result there is lack of synergistic interaction between the solid phases of biomass and coal (Idris et al., 2010; Kumabe et al., 2007). Studies by Bhagavatula et al. (2014), Idris et al. (2010) and Vuthaluru (2004) have reported on the use of agricultural waste or crops (i.e. corn stover, wheat straw and palm biomass waste) for co-processing with coal.

A new innovative approach, developed at the Institute of Chemical Technology (Nelson Mandela University, Port Elizabeth. South Africa), involves using live microalgae biomass to offer an alternative way to recover waste coal and to enable the incorporation of biomass components into waste coal thermal processing. The technology involves loading live microalgae slurries with waste coal fines to form coal-microalgae blends. The coal-microalgae blends could make it possible to yield a blend of biomass and fossil-based products in a single production process. Microalgae biomass has been identified as a potential bio-feedstock for co-processing with coal in this regard due to the added advantages of microalgae over agricultural crops or biomass wastes, such as that microalgae biomass are not dependent on fresh water for cultivation and thus do not contribute to water shortages, and have high areal productivity and high energy density (Mata et al., 2010; Brennan and Owende, 2010; Chisti, 2007; Miao et al., 2004).

In this study, microalgae biomass, in wet slurry form, is blended with waste coal fines at varying ratios, to form coal-microalgae blends. The influence of microalgae slurry on the chemical and thermal characteristics of waste coal fines were investigated. Determination of the proximate, ultimate and calorific values properties, as well as the thermal analysis under pyrolytic conditions were carried out for the parent samples (raw coal and pre-dried microalgae) and the coal-microalgae blends.

\section{Materials and methods \\ 2.1 Sample preparation}

A gross coal sample was prepared according to ASTM D2013, and pulverized on a Keegor Vertical Spindle Pulveriser to a particle size of $<250 \mu \mathrm{m}$, and further milled to obtain $a<150 \mu \mathrm{m}$ size. Scenedesmus microalgae biomass, cultivated in the integrated vertical column photo-bioreactor-raceway cultivation system at Nelson Mandela University (Port Elizabeth, South Africa), was harvested by concentrating the microalgae in the growth medium using natural settling in a settling pond overnight and returning the top layer of growth medium to the cultivation system. The concentrated microalgae slurry was collected and the concentration of the microalgae determined gravimetrically by evaporation of the residual water at $105^{\circ} \mathrm{C}$.

Concentration of microalgae (on a dry weight basis) was determined as the mass of dry microalgae (in grams) per gram of slurry harvested. The amount of microalgae slurry required to give a specific mass percentage loading on the waste coal fines was weighed and mixed with the desired mass of fine coal at $50 \mathrm{rpm}$ on a Heidolph RZR 2041 stir- 
rer overnight. Coal-microalgae composites were centrifuged at $4500 \mathrm{rpm}$ for ten minutes on a HERMLE Z 383 (Lasec SA) centrifuge. The aqueous fraction was decanted and the wet solids (coalmicroalgae blends) thoroughly washed with deionised water to remove any residual nutrients from the growth medium. Wet solids were oven-dried at $35^{\circ} \mathrm{C}$ overnight to prevent any major alteration in the coal structure and to ensure consistent drying conditions for all samples prepared. Oven dried coal-microalgae samples were further air-dried for three hours, with thorough mixing at every onehour interval. Lastly, the dried and conditioned coal-microalgae samples were ground using a pestle and mortar, and passed through a $250 \mu \mathrm{m}$ screen and stored in airtight containers. Coal-microalgae blends were prepared according to the following equation:

$$
\begin{aligned}
& \operatorname{MAR}(\mathrm{g})=[(\% \text { dry MA }) / 100) \\
& \left.\times(\mathrm{CMA}(\mathrm{g})) / \mathrm{MA}\left(\frac{\mathrm{g}}{\mathrm{g}}\right)\right]
\end{aligned}
$$

where MA denotes microalgae, CMA coal-microalgae, and MAR the microalgae slurry required.

\subsection{Proximate analysis of samples}

About 1.1 grams of each test sample was analysed on an Eltra Thermostep thermo-gravimetric analyser (TGA) that has an integrated programmable furnace, weighing balance and heating program. The TGA was used to perform an automated analysis of the moisture content $(\mathrm{MC})$, volatile matter (VM) and ash yield through the application of coal conventional standard methods (D-3173; D-3174; $\mathrm{D}-3175)$. The fixed carbon (FC) content is calculated by difference.

\subsection{Ultimate analysis of samples}

Determination of the elemental composition carbon $(\mathrm{C})$, hydrogen $(\mathrm{H})$, nitrogen $(\mathrm{N})$ and sulphur $(\mathrm{S})$ of the test samples was performed on a Vario EL Cube Elementar instrument. About 5 milligrams of each test sample, encapsulated in tin boats together with tungsten trioxide, was accurately weighed and loaded into a carousel. The samples were combusted at $1150{ }^{\circ} \mathrm{C}$ for 90 seconds in a combustion tube fitted with an oxygen injection lance. Measurements of sulphanilamide (5 milligrams) of known composition were carried out before analysis of test samples to ensure accurate measurements.

\subsection{Gross calorific value}

Measurements of the gross calorific values (GCV) of the test samples were done on a LECO AC 600 Bomb Calorimeter using the TruSpeed $(\AA$ method (ASTM D-5865). A benzoic acid pellet (about 1 gram) was used as a calibration sample.

\subsection{Thermo-gravimetric analysis}

A Mettler Toledo SDTA $851 \AA$ linked to a STAR $\AA$ software was used for the thermo-gravimetric analyses to study the thermal behaviour of the test samples under non-isothermal inert conditions. About $20 \mathrm{mg}$ of sample $(<150 \mu \mathrm{m})$ was weighed into a standard ceramic pan. Nitrogen gas (Baseline 5.0) was used to purge the system for 15 minutes at 100 $\mathrm{ml} / \mathrm{min}$. The experimental run was conducted by ramping from $40^{\circ} \mathrm{C}$ to $900{ }^{\circ} \mathrm{C}$ at $20^{\circ} \mathrm{C} / \mathrm{min}$, with a constant nitrogen flow of $80 \mathrm{ml} / \mathrm{min}$.

\section{Results and discussion}

As shown in Table 1, the parental coal has an ash yield of $20.8 \pm 0.12 \mathrm{wt}$. \% (d.b), and a volatile matter content (25.4 \pm 0.16 wt. \%, d.b); whereas the pure microalgae biomass has a low ash yield (7.3 \pm 0.11 wt. $\%$, d.b) with a high volatile matter content (77.5 \pm 0.43 wt. \%, d.b). The effects of loading microalgae slurry onto waste coal show that the volatile matter of coal is significantly increased (25.4 \pm 0.16 to $30.1 \pm 0.10$ wt. \%, d.b) at 10 wt. \% biomass loading, due to the contribution of high volatile matter of the microalgae biomass. The increase in the volatile matter corresponds to the decrease in the fixed carbon (53.8 \pm 0.14 to 50.3 \pm 0.20 wt. $\%$, d.b) at high biomass loadings. The observed trend in the volatile matter and fixed carbon contents of the test samples is indicative of the ignition and burn-out properties of the fuels (Chukwu et al., 2016; Vamvuka et al., 2006). This trend suggests that the presence of microalgae biomass in the waste coal fines will enhance the ignitability and thermal conversion of the waste coal fines. The reduction in the ash yield of the coal fines as the biomass loading is increased is minimal.

It can further be seen that the blending of microalgae biomass with waste coal at 5 and $10 \mathrm{wt}$. $\%$ loadings results in a systematic increase in the hydrogen content and a decrease in the carbon content. An expected increase in the oxygen content was observed, due to the contribution of oxygen-rich microalgae biomass. The relatively high oxygen content in the blends would be a factor contributing to the thermal reactivity of the fuels and can be used to predict the available active sites that can occur after devolatilization of the test samples (Hashimoto et al., 1986). Sulphur content values show a drop from $1.0 \pm 0.14 \mathrm{wt}$. \% for the coal to an average value $0.6 \mathrm{wt} . \%$ in the blends. Reduction in sulphur is attributable to the dilution effect as a result of loading microalgae slurry onto coal.

From the gross calorific value results, it can be seen that the blending of microalgae biomass with coal at 5 and 10 wt. \% loadings does not impact on the heating value of the raw coal fines. This can be expected given that the ash value of the blends does not vary to that of the raw coal; furthermore, 
Table 1: Chemical analyses of test samples.

\begin{tabular}{|c|c|c|c|c|c|}
\hline \multicolumn{6}{|c|}{ Proximate analysis (wt.\%, dry basis, d.b) } \\
\hline & $M C$ & $V M_{d . b}$ & $A S H_{d . b}$ & $F C_{d . b}$ & \\
\hline Microalgae & $8.1 \pm 0.06$ & $77.5 \pm 0.43$ & $7.3 \pm 0.11$ & $15.2 \pm 0.42$ & \\
\hline Raw coal & $5.4 \pm 0.09$ & $25.4 \pm 0.16$ & $20.8 \pm 0.12$ & $53.8 \pm 0.14$ & \\
\hline $5 \%$ blend & $4.6 \pm 0.03$ & $27.3 \pm 0.12$ & $20.3 \pm 0.13$ & $52.3 \pm 0.08$ & \\
\hline $10 \%$ blend & $4.7 \pm 0.51$ & $27.7 \pm 0.20$ & $20.3 \pm 0.47$ & $52.0 \pm 0.36$ & \\
\hline \multicolumn{6}{|c|}{$\overline{\mathrm{MC}}=$ moisture content; $\mathrm{VM}=$ volatile matter; $\mathrm{FC}=$ fixed carbon } \\
\hline \multicolumn{6}{|c|}{ Ultimate analysis (wt. \%, dry ash free (d.a.f) basis } \\
\hline & Carbon & Hydrogen & Nitrogen & Sulphur & Oxygen \\
\hline Microalgae & $56.4 \pm 0.22$ & $8.2 \pm 0.10$ & $9.9 \pm 0.06$ & $0.4 \pm 0.01$ & $25.1 \pm 0.39$ \\
\hline Raw coal & $79.3 \pm 0.59$ & $4.0 \pm 0.09$ & $2.2 \pm 0.30$ & $1.0 \pm 0.14$ & $13.4 \pm 0.85$ \\
\hline $5 \%$ blend & $74.1 \pm 0.11$ & $4.3 \pm 0.00$ & $2.1 \pm 0.11$ & $0.7 \pm 0.06$ & $18.8 \pm 0.67$ \\
\hline $10 \%$ blend & $73.6 \pm 0.08$ & $4.5 \pm 0.18$ & $3.0 \pm 0.01$ & $0.5 \pm 0.11$ & $18.4 \pm 0.22$ \\
\hline \multicolumn{6}{|c|}{ Gross calorific value } \\
\hline Sample & Microalgae & Raw coal & $5 \%$ blend & $10 \%$ blend & \\
\hline$\overline{\mathrm{MJ} / \mathrm{kg}}$ & $21.4 \pm 0.15$ & $23.7 \pm 0.30$ & $23.7 \pm 0.16$ & $23.5 \pm 0.14$ & \\
\hline
\end{tabular}

microalgae has a lower calorific value than raw coal, so blending at 5 and $10 \%$ loadings has minimal impact on the calorific value of the coal.

Thermal profiles (weight loss and derivative weight loss curves) showing the thermal behaviour under inert conditions during the pyrolysis of raw coal, microalgae and their respective blends are shown in Figures 1 to 3 .

As seen in Figure 1, pure microalgae degrades much easier and rapidly, than raw coal, which relates to bond strength of the molecular structure of the microalgae biomass, which is relatively weaker than that of coal (Vuthaluru, 2004). The peak temperature relating to microalgae degradation is at lower temperature $\left(\approx 300{ }^{\circ} \mathrm{C}\right)$, and this relates to the substantial release of the volatile matter.
Microalgae biomass degradation seems complete at lower reaction temperature as well $\left(<400^{\circ} \mathrm{C}\right)$. On the other hand, raw coal shows to have a slow degradation, its decomposition starting above 400 ${ }^{\circ} \mathrm{C}$, at a point where the active decomposition of pure microalgae has already ended. The observed slow decomposition could be attributed to the high carbon content of the parent coal (Ferrara et al. 2014). Moreover, coal consists of polycyclic aromatic hydrocarbons that are linked to heat-resistant aromatic bonds that results in lower weight loss rates (Cai et al., 2008; Moghtaderi et al., 2004).

As seen in Figure 2, the addition of microalgae biomass at $5 \%$ and $10 \%$ loadings improves the thermal degradation of coal. Weight loss of coal fines increase with increasing biomass loading, and

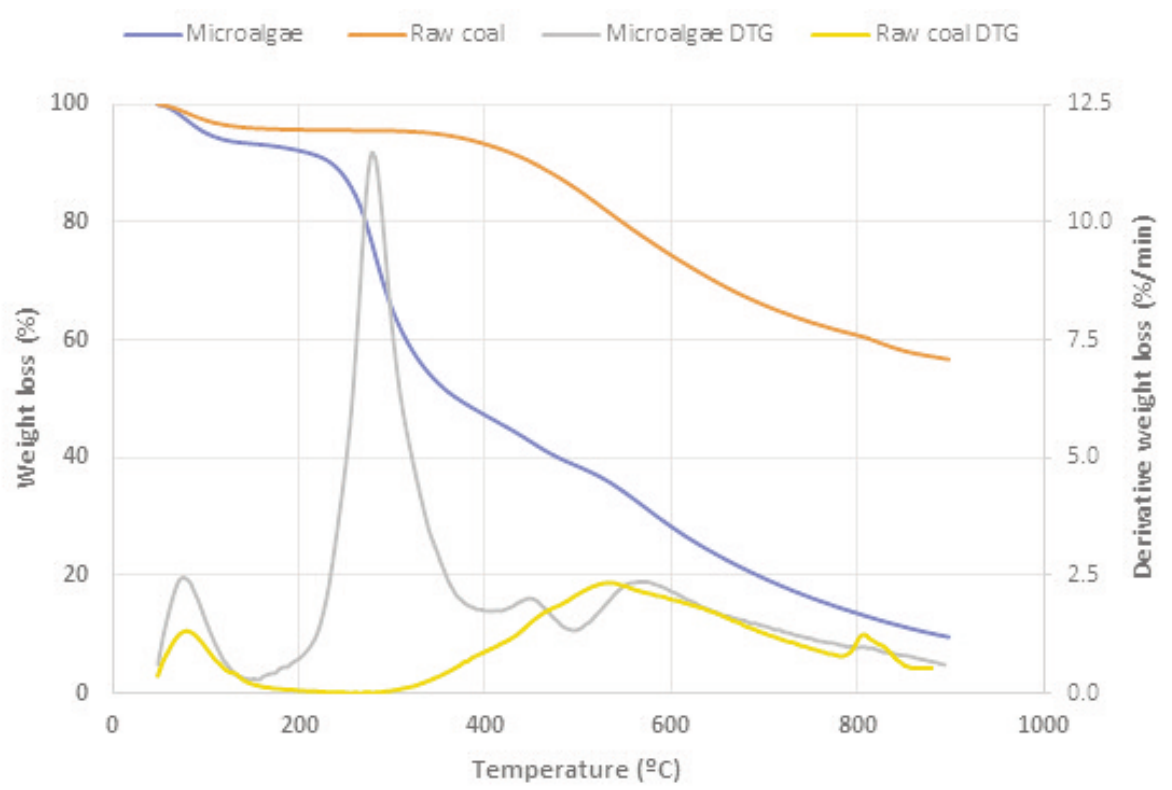

Figure 1: Weight loss curves of raw coal and microalgae. 


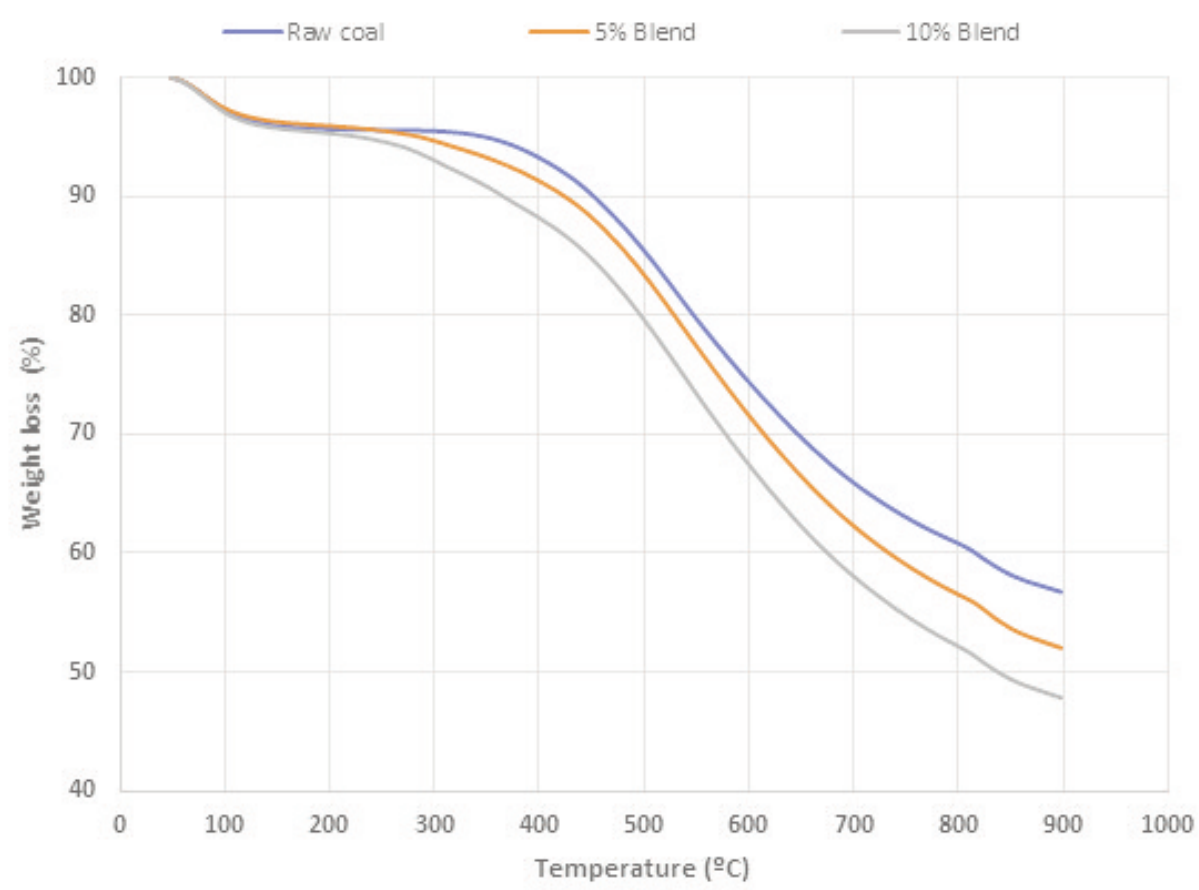

Figure 2: Weight loss curves for raw coal and coal-microalgae blends.

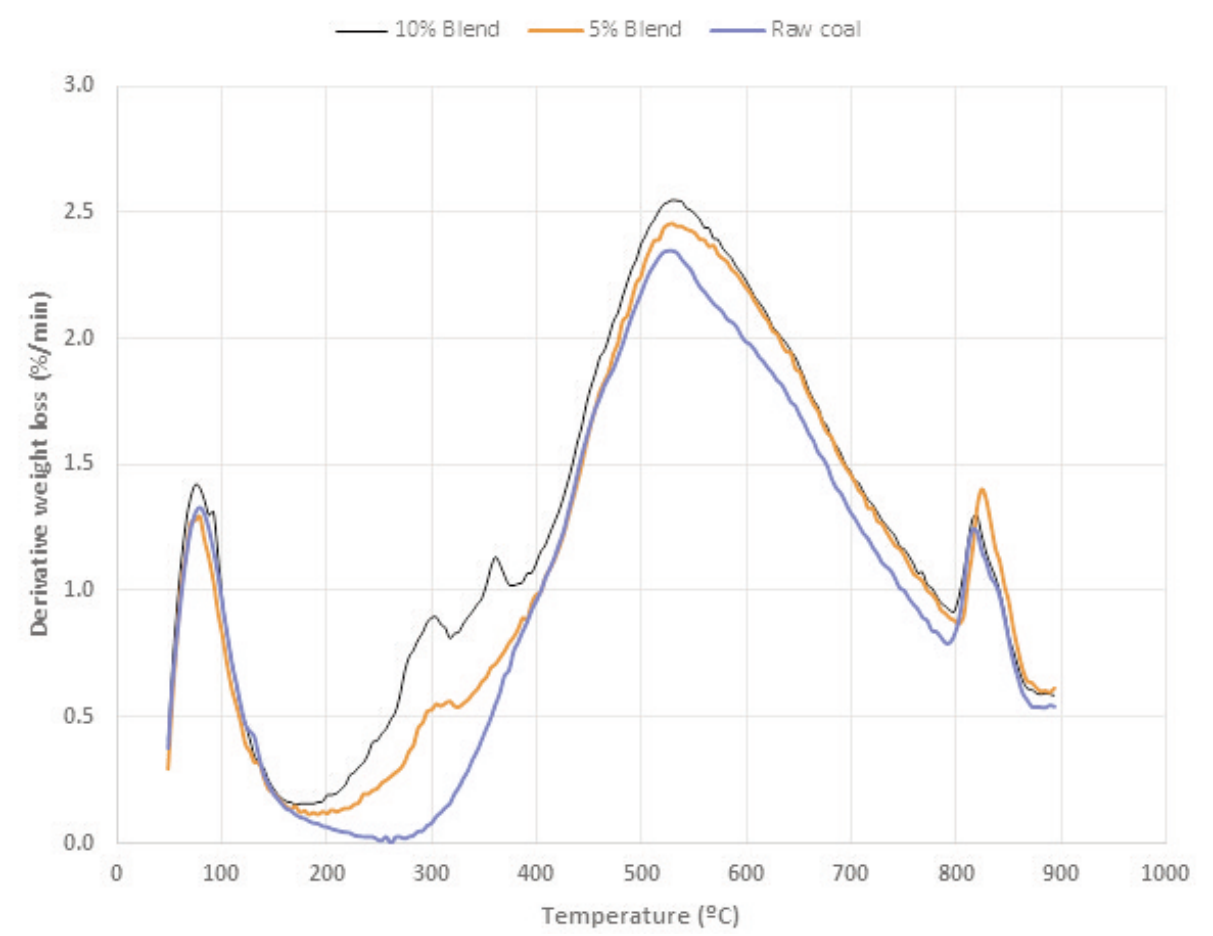

Figure 3: Derivative weight loss curves for raw coal and coal-microalgae blends.

result in lower residual mass fraction in the blend samples. This can be attributed to the high volatile matter content and lower fixed carbon at increased biomass loadings (Bhagavatula et al., 2014).

From Figure 3, It can be seen that at lower temperature range $\left(200-400{ }^{\circ} \mathrm{C}\right)$, the presence of microalgae facilitates the conversion of coal fines. At a low temperature range, coal exists in its metaplastic state (Quan and Gao, 2016), and therefore volatiles driven-off from microalgae biomass tend to influence the thermal behaviour of coal fines in that range. However, it is evident that the overall pyrolysis reaction of coal fines is not influenced by the presence of microalgae at higher temperatures above $400{ }^{\circ} \mathrm{C}$. This suggests that there is little opportunity for the volatile components of microalgae to interact meaningfully with the surfaces of coal or the volatiles of coal fines during thermal decomposition of the blends at increased temperatures. The degradation of the blends at temperatures above $400{ }^{\circ} \mathrm{C}$ follows that of coal when decomposed alone. 


\section{Conclusions}

The blending of microalgae biomass (in slurry form) with waste coal fines was found to have an influence on the chemical composition of the coal fines but has no impact on the calorific value of the coal. Coal-microalgae blends present an increase in the volatile matter content, reduction in the fixed carbon, and an improved hydrogen content. The overall thermal behaviour of the coal-microalgae blends reflects the effects of adding microalgae slurry onto coal. The presence of microalgae at increased biomass ratio had obvious effects on the rate of decomposition of coal at the lower temperature range as well as on the residual mass fraction at the end of decomposition under inert atmosphere. Blending microalgae biomass with coal may be a suitable way to enhance the thermal conversion and effective utilisation of waste coal.

\section{Acknowledgements}

This research was supported by the Department of Science and Technology through the National Research Foundation. Opinions expressed and conclusions arrived at are those of the author and are not necessarily to be attributed to the National Research Foundation.

\section{References}

Bhagavatula, A., Huffman, G., Shah, N and Honaker, R. 2014. Evaluation of thermal evolution profiles and estimation of kinetic parameters for pyrolysis of coal/corn stover blends using thermogravimetric analysis. Journal of Fuels 2014: Article ID 914856. $1-12$

Blesa, M.J., Miranda, J.L., Moliner, R and Izquierdo, M.T. 2003. Low-temperature co-pyrolysis of a lowrank coal and biomass to prepare smokeless fuel briquettes. Journal of Analytical and Applied Pyrolysis 70 (2): 665-677. https://doi.org/10.1016/S0165-2370(03)00047-0

Brennan, L and Owende, P, 2010. Biofuels from microalgae: A review of technologies for production, processing, and extraction of biofuels and co-products: Journal of Renewable and Sustainable Energy Reviews 14 (2): 557-577.

https://doi.org/10.1016/j.rser.2009.10.009

BP 2015. BP statistical review on world energy. Available online at http://bp.com/statisticalreview.

Cai, J., Wang, Y. and Zhou, L. 2008.

Thermogravimetric analysis and kinetics of coal/plastic blends during co-pyrolysis in nitrogen atmosphere. Fuel Processing Technology 89 (1): 21-27. https://doi.org/10.1016/j.fuproc.2007.06.006

Chao, C.Y.H., Kwong, P.C.W., Wang, J.H., Cheung, C.W and Kendall, G. 2008. Co-firing coal with rice husk and bamboo and the impact on particulate matters and associated polycyclic aromatic hydrocarbon emissions. Bioresource Technology 99 (1): 8393 https://doi.org/10.1016/j.biortech.2006.11.051

Chen, C., Ma, $\square$ and He, Y. 2012. Co-pyrolysis characteristics of microalgae Chlorella vulgaris and coal through TGA. Bioresource Technology 117. 264 273.

Chisti, Y. 2007. Biodiesel from microalgae: Journal of Biotechnology Advances. 25 (3): 294-306. https://doi.org/10.1016/j.biotechadv.2007.02.001

Chukwu, M., Folayan, G.Y., Pam, G.Y. and Obad, D.O 2016. Characterization of some Nigerian coals for power generation. Journal of Combustion: 2016 Article ID 9728278, 1-11.

Department of Minerals and Energy. 1998. White Paper on the Energy Policy of the Republic of South Africa (RSA)

Debiagi, P, E, A., Trinchera, M., Frassoldati, A., Faravelli, T., Vinu, R and Ranzi, E. 2017. Algae characterization and multistep pyrolysis mechanism. Journal of Analytical and Applied Pyrolysis 128: 423-436. https://doi.org/10.1016/j.jaap.2017.08.007

Ferrara, F., Orsini, A., Plaisant, A., Pettinau, A. 2014. Pyrolysis of coal, biomass and their blends: Performance assessment by thermogravimetric analysis. Bioresource Technology: 171. 433-441. https://doi.org/10.1016/j.biortech.2014.08.104

Fermoso, J., Arias, B., Gil, M.V., Plaza, M.G., Pevida, C., Pis, J.J and Rubiera, F. 2010. Co-gasification of different rank coals with biomass and petroleum coke in a high-pressure reactor for $\mathrm{H}_{2}$ - rich gas production. Bioresource Technology 101 (9): 32303235. https://doi.org/10.1016/j.biortech.2009.12.035

Gaqa, S and Watts, P. 2018. The agglomeration of coal fines using microalgae biomass. Journal of Energy in Southern Africa 29 (2): 43-50. https://doi.org/10.17159/24133051/2018/v29i2a3469

Hashimoto, K., Miura, K. and Ueda, T. 1986. Correlation of gasification rates of various coals measured by a rapid heating method in a steam atmosphere at relatively low temperatures. Fuel 65 (11):1516-1523. https://doi.org/10.1016/0016-2361(86)90327-3

Idris, S.S., Rahman, N.A., Ismail, K., Alias, A.B., Rashid, Z.A and Aris, M.J. 2010. Investigation on thermochemical behaviour of low rank Malaysian coal, tar palm biomass and their blends during pyrolysis via thermo gravimetric analysis. Bioresource Technology 101 (12): 4584-4592. https://doi.org/10.1016/j.biortech.2010.01.059

Kirtania, K and Bhattacharya, S. 2013. Pyrolysis kinetics and reactivity of algae-coal blends. Biomass and Bioenergy 55: 291-298. https://doi.org/10.1016/j.biombioe.2013.02.019

Kumabe, K., Hanaoka, T., Fujimoto, S., Minowa, T and Sakanishi, K. 2007. Co-gasification of woody biomass and coal with air and steam. Fuel 86 (5-6): 684-689. https://doi.org/10.1016/j.fuel.2006.08.026

Mata, M.T., Martins, A.A. AND Caetano, N.S. 2010. Microalgae for biodiesel production and other appli- 
cations: A review. Journal of Renewable and Sustainable Energy Reviews 14 (1): 217-232. https://doi.org/10.1016/j.rser.2009.07.020

Miao, X.L., Wu, Q.Y and Yang, C.Y. 2004. Fast pyrolysis of microalgae to produce renewable fuels. Journal of Analytical and Applied Pyrolysis 71 (2): 855-863. https://doi.org/10.1016/j.jaap.2003.11.004

Moghtaderi, B., Meesri, C and Wall, T.F. 2004. Pyrolytic characteristics of blended coal and woody biomass. Fuel 83 (6): 745-750.

https://doi.org/10.1016/j.fuel.2003.05.003

Quan, C and Gao, N. 2016. Copyrolysis of biomass and coal: A review of effects of parameters, product properties, and synergistic mechanisms. BioMed Research International. 2016, Article ID 6197867, $1-11$.

Vamvuka, D, Kakaras, E, Kastanaki, E and Grammelis. P. 2003. Pyrolysis characteristics and kinetics of biomass residuals mixtures with lignite. Fuel 82 (1517): 1949-1960. https://doi.org/10.1016/S0016-2361(03)00153-4

Vuthaluru, H.B. 2004. Thermal behaviour of coal/biomass blends during co-pyrolysis. Fuel Processing Technology 85 (2-3): 141-155. https://doi.org/10.1016/S0378-3820(03)00112-7

World Coal Institute. WCI. 2007. The coal resource: A comprehensive overview of coal. Available online at http://www.worldcoal.org.

Zhang, L., Au, S and Liu, S. 2007. Co-pyrolysis of biomass and coal in a free fall reactor. Fuel 86 (3): 353-359.

https://doi.org/10.1016/j.fuel.2006.07.004 